\title{
Financial Incentives for Extended Weight Loss: A Randomized, Controlled Trial
}

\author{
Leslie K. John, $\mathrm{MS}^{7}$, George Loewenstein, $P h D^{1,2}$, Andrea B. Troxel, ScD ${ }^{2,3}$, Laurie Norton, MA ${ }^{2,4,5}$, \\ Jennifer E. Fassbender, $M S^{3}$, and Kevin G. Volpp, MD, PhD 2,4,5,6
}

'Department of Social and Decision Sciences, Carnegie Mellon University, Pittsburgh, PA, USA; ${ }^{2}$ Center for Health Incentives, Leonard Davis Institute of Health Economics, University of Pennsylvania, Philadelphia, PA, USA; ${ }^{3}$ Center for Clinical Epidemiology and Biostatistics and Department of Biostatistics and Epidemiology, University of Pennsylvania, Philadelphia, PA, USA; ${ }^{4}$ Center for Health Equity Research and Promotion, Philadelphia Veterans Affairs Medical Center, Philadelphia, PA, USA; ${ }^{5}$ Department of Medicine, University of Pennsylvania School of Medicine, Philadelphia, PA, USA; ${ }^{6}$ Department of Health Care Management, The University of Pennsylvania Wharton School, Philadelphia, PA, USA.

BACKGROUND: Previous efforts to use incentives for weight loss have resulted in substantial weight regain after 16 weeks.

OBJECTIVE: To evaluate a longer term weight loss intervention using financial incentives.

DESIGN: A 32-week, three-arm randomized controlled trial of financial incentives for weight loss consisting of a 24-week weight loss phase during which all participants were given a weight loss goal of 1 pound per week, followed by an 8-week maintenance phase.

PARTICIPANTS: Veterans who were patients at the Philadelphia Veterans Affairs Medical Center with BMIs of 30-40.

INTERVENTION: Participants were randomly assigned to participate in either a weight-monitoring program involving a consultation with a dietician and monthly weigh-ins (control condition), or the same program with one of two financial incentive plans. Both incentive arms used deposit contracts (DC) in which participants put their own money at risk (matched 1:1), which they lost if they failed to lose weight. In one incentive arm participants were told that the period after 24 weeks was for weight-loss maintenance; in the other, no such distinction was made.

MAIN MEASURE: Weight loss after 32 weeks.

KEY RESULTS: Results were analyzed using intention-to-treat. There was no difference in weight loss between the incentive arms $(P=0.80)$. Incentive participants lost more weight than control participants [mean DC $=8.70$ pounds, mean control $=1.17, P=$ $0.04,95 \% \mathrm{CI}$ of the difference in means $(0.56,14.50)]$. Follow-up data 36 weeks after the 32-week intervention had ended indicated weight regain; the net weight loss between the incentive and control groups was no longer significant (mean $\mathrm{DC}=1.2$ pounds, 95\% CI, -2.58-5.00; mean control $=0.27,95 \% \mathrm{CI}$, -3.77-4.30, $P=0.76)$.

CONCLUSIONS: Financial incentives produced significant weight loss over an 8-month intervention; however, participants regained weight post-intervention.

Received July 9, 2010

Revised October 11, 2010

Accepted December 27, 2010

Published online January 20, 2011
KEY WORDS: behavioral medicine; obesity; psychology; randomized trials; behavioral economics.

$\mathrm{J}$ Gen Intern Med 26(6):621-6

DOI: $10.1007 / \mathrm{s} 11606-010-1628-y$

(c) Society of General Internal Medicine 2011

\section{INTRODUCTION}

The obesity rate within the United States is high, with $31 \%$ of the US population obese and $71 \%$ of US adults overweight or obese. ${ }^{1}$ Weight loss interventions have generally been unsuccessful in achieving sustained weight loss. Numerous studies have shown that programs are at best only modestly successful in helping individuals lose weight and keep it off. ${ }^{2-5}$

Behavioral economics-the application of psychological insights to standard economics-is emerging as a key discipline in modifying self-destructive behaviors, such as those leading to obesity. Whereas standard economics is premised on a rational choice model and assumes that individuals make decisions optimally, behavioral economics not only acknowledges that behavior is often suboptimal, but also identifies decision errors and judgmental biases that contribute to such departures from optimality. This paper contributes to a growing body of research demonstrating that the same decision errors that often result in self-destructive behavior can instead be used to help people engage in behaviors that are consistent with their long-term interests. $^{6}$

We tested the effectiveness of a longer term version of a previous weight loss intervention ${ }^{7}$ that used loss aversion-the tendency for people to put substantially greater weight on losses than gains ${ }^{8}$ - to magnify the impact of incentives. In this financial incentive plan, participants voluntarily enter into a pre-commitment or deposit contract, in which their own money is put at risk such that they lose money if they are unsuccessful in losing weight. We randomized participants to a control group, a deposit contract group with the final 8 weeks of the intervention framed as a period of weight loss maintenance, or a deposit contract group in which the entire period was framed as a weight loss program.

We extended our previous work in three ways. First, participants in the study by Volpp et al. ${ }^{7}$ re-gained a substantial 
amount of weight that they had lost during the intervention, which was only 16 weeks long. The present study tested whether financial incentives for weight loss can lead to longer term weight loss and maintenance; the intervention was therefore increased to 8 months. Second, we tested a possible explanation for the substantial weight regain seen during the maintenance phase following the 16-week intervention-that the very label 'maintenance' may have caused participants to be less vigilant in controlling their weight. Finally, participants in the study by Volpp et $a .^{7}$ were given a $\$ 3$ fixed payment each day that they attained their weight loss goals (in addition to having their deposit contracts matched). In the present study, we eliminated the fixed payment, enabling us to (1) isolate the effect of deposit contracts and (2) test a plausibly more cost-effective intervention.

\section{METHODS}

Design Overview. The study was a 32 -week, three-arm randomized controlled trial consisting of a 24-week weight loss phase during which all participants were given a weight loss goal of 1 pound per week, followed by an 8-week maintenance phase in which participants were not required to lose weight. This was included to assess the impact of framing this period as 'maintenance' vs. an ongoing opportunity for continued weight loss. To assess longer term maintenance following the 32-week intervention, participants returned for a weigh-in approximately 36 weeks after the last participant had completed the 32-week intervention.

Setting and Participants. Participants were 66 obese patients from the Philadelphia Veterans Affairs Medical Center (PVAMC). The flow of participants through enrollment, intervention, and follow-up is shown in Figure 1. Participants meeting initial eligibility requirements were identified through a PVAMC patient database; a randomly selected subset was recruited using mailings; those interested were screened for eligibility. The minimum participation age was 30 years; a lower age risks having too mixed a group from an intervention perspective. The upper age limit was 70 years; evidence for the benefit of weight reduction after 70 is relatively weak. ${ }^{9}$ The upper BMI limit was 40 to minimize the influence of outliers on the results. The exclusion criteria were otherwise limited to

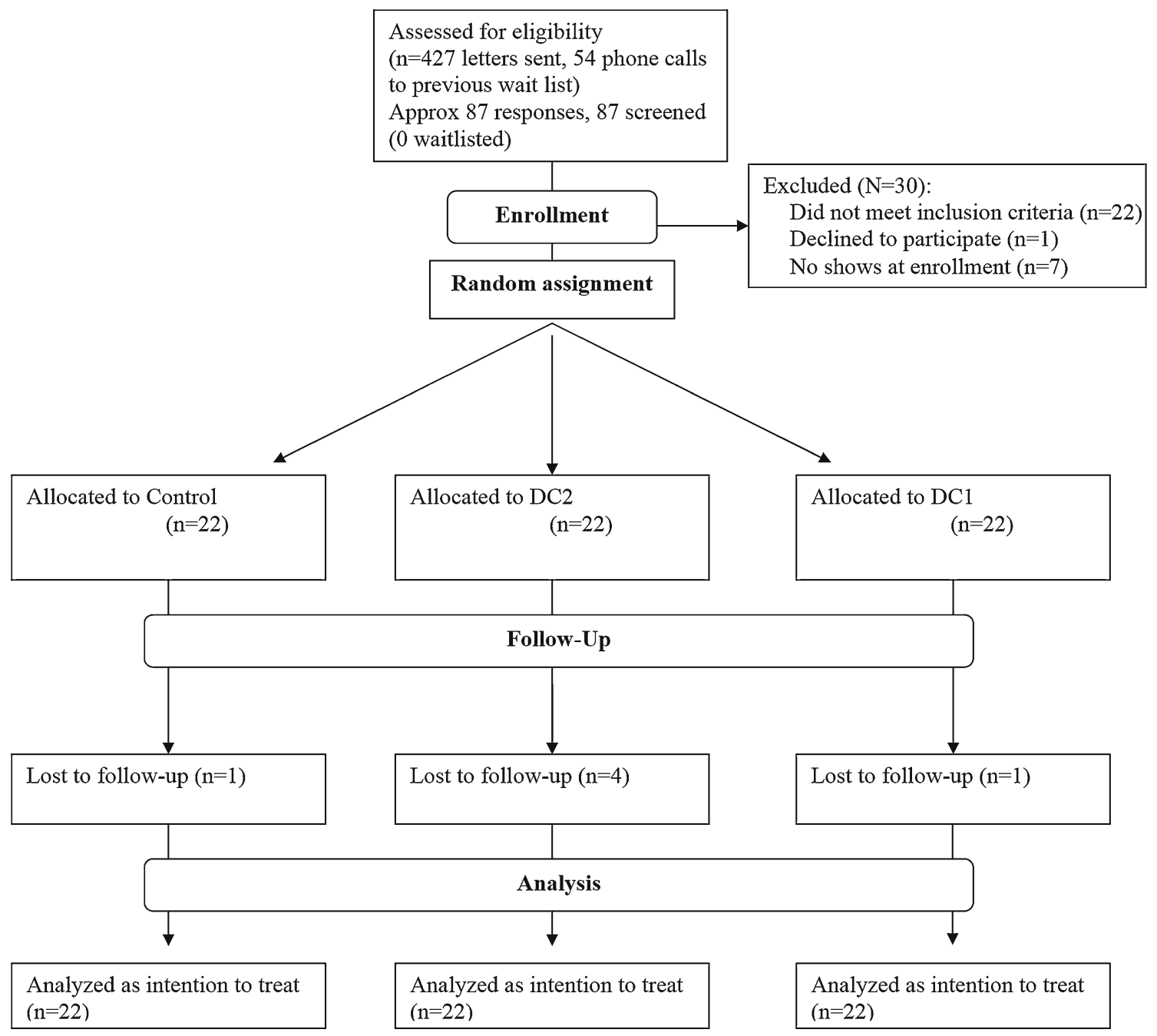

Figure 1. Flow of study participants. 
conditions making participation either infeasible (e.g. illiteracy) or unsafe (e.g., serious psychiatric diagnoses). Recruitment began in June 2008 and ended in September 2008; follow-up ended in January 2010. Participants provided signed, written informed consent. The protocol was approved by the PVAMC's IRB.

Randomization and Interventions. Participants were randomized evenly to participate in a weight-monitoring program (control condition) or the same program with one of two financial incentive plans (deposit contract condition, hereafter referred to as DC) using a block size of six, with stratification based on sex and age (30-49 vs. 50-70).

The weight-monitoring program consisted of: a 1-h, one-onone consultation with a dietician at enrollment in which strategies for weight loss were discussed, goal setting, and monthly weigh-ins.

Participants were given a weight loss target of 24 pounds in the first 24 weeks. The weight loss goal was imposed because allowing participants to choose their own goals would have made it impossible to separate the possible effect of individual differences in goal setting on weight loss from the pure effect of incentives. However, people often choose goals that are more stringent than the minimum that would be economically rational; ${ }^{10}$ therefore, in the second phase, participants who attained the 24 pound weight loss goal could choose a goal of $0,0.5$, or 1 pound per week for weeks 25-32 of the study.

Participants received a scale to monitor their weight at home. At the end of each month, participants received $\$ 20$ for returning to the clinic to be weighed.

DC participants were given a chart at the initial visit depicting the daily weight goals to attain to qualify for incentives and a hand-out describing the incentive plan. At the beginning of each month, DC participants could contribute between \$0.00-\$3.00 per day of their own funds to a deposit contract. During the month, participants accumulated rewards: for each day that a participant called in and reported a weight at or below his weight loss goal, he accumulated a reward equal to his daily deposit, plus a 1:1 match from us. Participants were aware, however, that they would only receive accumulated awards if they weighed at or below their weight loss goal at the end of the month weigh-in. Thus, these participants could earn $\$ 84$ net (\$168 gross) per month (i.e., by making the maximum $\$ 3.00$ daily deposit, and on every day of the month, truthfully reporting that they had attained their daily weight loss goal).

DC participants were instructed to: (1) weigh themselves each morning before eating or drinking and after urinating, (2) record their weights, and (3) call in their weight by noon. Every day, they were sent a text message indicating whether they were on track toward attaining their monthly weight loss goal and how much they had earned that day in incentives. Participants who sent their morning weights received rapid, same-day feedback about their progress and earnings. Nonadherent participants received feedback about what they would have earned had they met their target weight.

For half of the DC participants, the first 24 weeks of the study were described, in both written and verbal communication to participants, as the 'weight loss period;' the final 8 weeks (i.e., weeks 25-32) were framed as the 'maintenance of weight loss period' (DC1). The second incentive condition was the same except that there was no explicit distinction between the two periods of the study (DC2), which was also the case in the control condition.

Deposit contract money that was forfeited by participants failing to lose sufficient weight was contributed to a pool of money divided equally among DC participants who lost 20 pounds or more by the end of 24 weeks.

A key feature of the weight loss trajectory is that it was reset at monthly intervals for those failing to attain goals. For those who had surpassed their goals, the trajectory was flattened; such individuals could then lose weight at a slower rate and still attain the final 24-pound weight loss goal. Participants above their goal at the end of a month were given a "fresh start" in which the overall goal was unchanged, but the slope of the trajectory was adjusted (i.e., steepened) such that the participant need not "binge diet" to resume receiving incentive payments. Keeping the overall weight loss goal constant made the procedure fair for those who maintained the ideal trajectory, while helping participants who lapsed to get back on track.

\section{Outcome and Follow-Up}

The primary outcome was weight loss after 32 weeks. The secondary outcome measure was weight loss maintenance 36 weeks after the 32-week intervention had ended.

Participants lost to follow-up were treated as having reverted to baseline weight.

\section{Statistical Analysis}

Power calculations were based on detecting clinically significant weight loss ${ }^{11}$ : weight loss of 11 pounds (5 kg) at 32 weeks. Making the assumption of an 11-pound standard deviation for weight loss and using a two-sided alpha of 0.025 , we required 22 participants per arm to provide $90 \%$ power to detect clinically significant differences between groups.

Pearson's $x^{2}$ test or Fisher's exact test was used for categorical variables, as appropriate; t-tests or Wilcoxon rank sum for continuous variables, as appropriate. All tests were two-sided.

\section{RESULTS}

Baseline characteristics of the three groups were generally equivalent (Table 1), with the exception of three variables: (1) importance of controlling weight $[$ control $=9.05, \mathrm{DC} 1=9.56$, $\mathrm{DC} 2=7.67, \mathrm{~F}(2,66)=3.84, P=0.03]$; (2) proportion using tobacco $[$ control $=13.6 \%, \mathrm{DC} 1=31.8 \%, \mathrm{DC} 2=4.5 \% ; \times 2(2)=$ 6.11, $P=0.05)]$; (3) self-rated health $($ control $=3.1 / 5, \mathrm{DC} 1=$ $3.7 / 5, \mathrm{DC} 2=3.0 / 5, P=0.03$ ). There were differences in marital status and household income that were possibly clinically, though not statistically, significant (Table 1). The results do not change substantively when controlling for these variables. At the primary outcome point, ten percent of participants were lost to follow-up $(\mathrm{C}=1 / 22, \mathrm{DC} 1=1 / 22, \mathrm{DC} 2=4 / 22, P=0.35$, Fisher's exact test). 
Table 1. Characteristics of the Study Sample

\begin{tabular}{|c|c|c|c|}
\hline Participant characteristics & $\begin{array}{l}\text { Control } \\
(n=22)\end{array}$ & $\begin{array}{l}\mathrm{DCl} \\
(n=22)\end{array}$ & $\begin{array}{l}\text { DC2 } \\
(n=22)\end{array}$ \\
\hline Male & $18(81.8)$ & $18(81.8)$ & $19(86.4)$ \\
\hline \multicolumn{4}{|l|}{ Race/ethnicity } \\
\hline Black & $9(40.1)$ & $14(63.6)$ & $13(59.1)$ \\
\hline White & $10(45.5)$ & $7(31.8)$ & $9(40.9)$ \\
\hline Hispanic & $2(9.1)$ & 0 & 0 \\
\hline $\begin{array}{l}\text { American Indian or Alaskan } \\
\text { Native }\end{array}$ & $1(4.5)$ & 0 & 0 \\
\hline Married & $17(77.3)$ & $10(45.5)$ & $11(52.4)$ \\
\hline \multicolumn{4}{|l|}{ Education } \\
\hline Some high school & $2(9.1)$ & 0 & $3(13.6)$ \\
\hline Completed high school or GED & $8(36.4)$ & $8(38.1)$ & $8(36.4)$ \\
\hline Some college or higher & $12(54.5)$ & $13(59.0)$ & $11(50.0)$ \\
\hline $\begin{array}{l}\text { Median total annual household } \\
\text { income }\end{array}$ & $\$ 48,500$ & $\$ 32,500$ & $\$ 35,550$ \\
\hline Height (sd) & $\begin{array}{l}5 ' 8^{\prime \prime} \\
\left(3.0^{\prime \prime}\right)\end{array}$ & $\begin{array}{l}5^{\prime} 7^{\prime \prime} \\
\left(2.9^{\prime \prime}\right)\end{array}$ & $\begin{array}{l}5^{\prime} 7^{\prime \prime} \\
\left(3.4^{\prime \prime}\right)\end{array}$ \\
\hline \multicolumn{4}{|l|}{ Initial weight measurement } \\
\hline In pounds (sd) & $\begin{array}{l}230.9 \\
(23.9)\end{array}$ & $\begin{array}{l}227.7 \\
(23.3)\end{array}$ & $\begin{array}{l}231.2 \\
(31.9)\end{array}$ \\
\hline BMI (sd) & $\begin{array}{l}34.7 \\
(3.2)\end{array}$ & $\begin{array}{l}35.1 \\
(2.4)\end{array}$ & $\begin{array}{l}34.1 \\
(2.8)\end{array}$ \\
\hline $\begin{array}{l}\text { Self-rated health measured on a } \\
1-5 \text { scale; endpoints labeled } \\
\text { "poor" and "excellent" (sd) }\end{array}$ & $\begin{array}{l}3.05 \\
(0.90)\end{array}$ & $\begin{array}{l}3.68 \\
(0.95)\end{array}$ & $\begin{array}{l}3.00 \\
(0.93)\end{array}$ \\
\hline $\begin{array}{l}\text { Self-rated importance of controlling } \\
\text { weight }{ }^{*}(\mathrm{sd})\end{array}$ & $\begin{array}{l}9.05 \\
(1.39)\end{array}$ & $\begin{array}{l}9.56 \\
(0.92)\end{array}$ & $\begin{array}{l}7.67 \\
(2.34)\end{array}$ \\
\hline $\begin{array}{l}\text { Confidence in ability to lose } \\
\text { weight (sd) }\end{array}$ & $\begin{array}{l}8.37 \\
(1.89)\end{array}$ & $\begin{array}{l}8.39 \\
(2.57)\end{array}$ & $\begin{array}{l}8.00 \\
(1.64)\end{array}$ \\
\hline \multicolumn{4}{|l|}{ Physical health comorbidities } \\
\hline Shortness of breath at rest & $1(4.5)$ & $5(22.7)$ & $1(4.5)$ \\
\hline $\begin{array}{l}\text { Chest pains not evaluated by } \\
\text { physician }\end{array}$ & 0 & $1(4.5)$ & 0 \\
\hline Active infection & 0 & $9.1(2)$ & 0 \\
\hline Hernia in groin or belly area & $2(9.1)$ & $2(9.1)$ & $2(9.1)$ \\
\hline Retinal hemorrhage & 0 & 0 & 0 \\
\hline Loss of balance $^{\dagger}$ & 0 & $1(4.5)$ & $2(22.7)$ \\
\hline Chronic medical problem flare-up & $2(9.1)$ & $4(18.2)$ & $6(27.3)$ \\
\hline Back pain or spinal disc disease & $9(40.9)$ & $11(50.0)$ & $63.6(14)$ \\
\hline Osteoporosis or bone disease & $3(13.6)$ & $3(13.6)$ & $1(4.5)$ \\
\hline Amputation & 0 & 0 & 0 \\
\hline Spinal cord injury & 0 & 0 & $9.1(2)$ \\
\hline Lung disease & $4(18.2)$ & $4(18.2)$ & $1(4.5)$ \\
\hline Heart disease & $2(9.1)$ & $2(9.1)$ & $6(27.3)$ \\
\hline Poor circulation & $1(4.5)$ & $1(4.5)$ & $4(18.2)$ \\
\hline $\begin{array}{l}\text { Stroke, TIAs or carotid surgery } \\
\text { in neck }\end{array}$ & $1(4.5)$ & 0 & 0 \\
\hline Diabetes & $1(4.5)$ & $3(13.6)$ & $4(18.2)$ \\
\hline High blood pressure & $15(68.2)$ & $12(54.5)$ & $14(63.6)$ \\
\hline High blood cholesterol & $13(59.1)$ & $6(27.3)$ & $10(45.5)$ \\
\hline $\begin{array}{l}\text { Family member with heart } \\
\text { problems at age younger than } 50\end{array}$ & $3(13.6)$ & $2(9.1)$ & $2(9.1)$ \\
\hline \multicolumn{4}{|c|}{ Psychological and/or chemical comorbidities } \\
\hline Too much stress & $6(27.3)$ & $5(22.7)$ & $8(36.4)$ \\
\hline General unhappiness & $4(18.2)$ & $5(22.7)$ & $4(18.2)$ \\
\hline Depression & $7(31.8)$ & $6(27.3)$ & $9(40.9)$ \\
\hline Anxiety problems & $6(27.3)$ & $5(22.7)$ & $4(18.2)$ \\
\hline Family or relationship problems & $7(31.8)$ & $6(27.3)$ & $4(18.2)$ \\
\hline Bipolar disorder & 0 & $1(4.5)$ & $1(4.5)$ \\
\hline Schizophrenia & 0 & 0 & 0 \\
\hline
\end{tabular}

Weight Loss. Mean weight loss at 32 weeks was not statistically different between the two incentive arms (mean DC1 $=9.65$ pounds, $\mathrm{SD}=13.62 ;$ mean $\mathrm{DC} 2=7.75$ pounds, $\mathrm{SD}=12.82$; $\mathrm{F}(1,41)=0.064, P=0.80$ ] (Fig. 2). Therefore, for the remaining analyses, we pooled the incentive conditions together. Mean weight loss at 32 weeks was statistically greater in the
Table 1. (continued)

\begin{tabular}{llll}
\hline \hline Participant characteristics & $\begin{array}{l}\text { Control } \\
(\mathbf{n = 2 2})\end{array}$ & $\begin{array}{l}\text { DC1 } \\
(\mathbf{n = 2 2})\end{array}$ & $\begin{array}{l}\text { DC2 } \\
(\mathbf{n}=22)\end{array}$ \\
\hline Post-traumatic stress disorder & $11(50)$ & $7(31.8)$ & $8(36.4)$ \\
Obsessive compulsive disorder & 0 & $2(9.1)$ & 0 \\
Eating disorder & $1(4.5)$ & $1(4.5)$ & $2(9.1)$ \\
Tobacco use & $3(13.6)$ & $7(31.8)$ & $1(4.5)$ \\
Substance abuse or dependence & 0 & $1(4.5)$ & 0 \\
\hline
\end{tabular}

Unless otherwise noted, numbers in parentheses represent the percent of participants within the condition (column) that have the given attribute. Note: In a few cases, the denominator is $<22$, since not all respondents answered every question.

Abbreviations: BMI, body mass index, calculated as weight in kilograms divided by height in meters squared; GED, general education development Conversion factor: To convert from pounds to kilograms, multiply by 0.45 ; from feet to meters, multiply by 0.3 ; and inches to centimeters, multiply by 2.54

Differences between conditions significant at alpha $<0.05$, two-tailed

incentive groups $(\mathrm{DC}=8.70$ pounds) relative to the control arm $(\mathrm{C}=1.17$ pounds) $[t(64)=2.16, P=0.04,95 \% \mathrm{CI}$ of the difference in means $(0.56,14.50)]$ (Table 2).

At 24 weeks - the end of the weight loss phase of the study$10.6 \%$ of participants had attained the goal of losing 24 pounds; this rate was not different between conditions [mean $\mathrm{C}=9.1 \%(2 / 22)$, mean $\mathrm{DC}=11.4 \%(5 / 44), \chi^{2}(1)=0.080, P=$ 0.78]. Similarly, the proportion of participants who had attained and maintained a 24-pound weight loss at 32 weeks was low and similar across arms [mean $C=9.1 \%(2 / 22)$, mean $\left.\mathrm{DC}=13.6 \%(6 / 44), \chi^{2}(1)=0.284, P=0.59\right]$.

Participants in the DC groups who had lost at least 20 pounds by the end of 32 weeks each received $\$ 467.80$ (their share of the money forfeited by participants in the DC arms who did not attain their goals).

Goal Setting. Participants who had attained the 24-pound weight loss goal by the end of 24 weeks could choose to

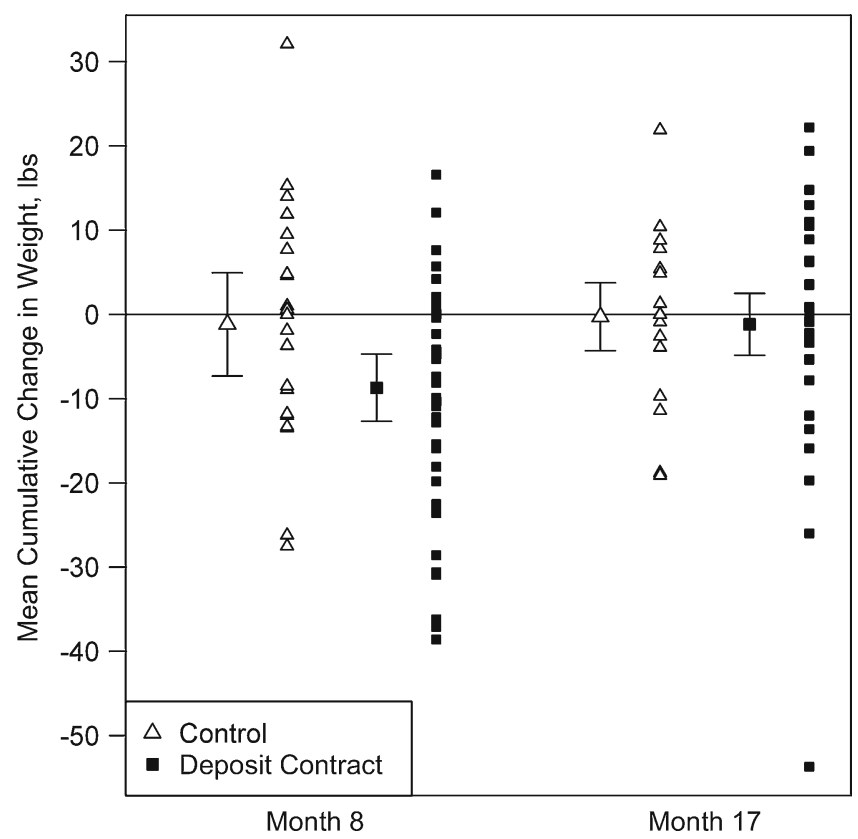

Figure 2. Mean cumulative weight loss at 8 months (primary outcome measure) and approximately 17 months. 
Table 2. 32-Week Weight Loss Measures by Group

\begin{tabular}{llll}
\hline \hline Measure & Control $(n=22)$ & DC1 $(n=22)$ & DC2 $(n=22)$ \\
\hline \multicolumn{2}{l}{ Total weight loss, pounds } & & \\
Mean ${ }^{*}$ (SD) & $1.2(13.8)$ & $9.6(13.6)$ & $7.6(12.8)$ \\
$95 \%$ CI & 5.0 (gain)-7.3 & $3.6-15.7$ & $2.1-13.4$ \\
Met 24-pound weight loss goal by week 32 & \\
Number (\%) & 2 (9.1) & $4(18.2)$ & $2(9.1)$ \\
95\% binomial CI & $1.1-29.2$ & $5.2-40.3$ & $1.1-29.2$ \\
\hline
\end{tabular}

Abbreviation: CI, confidence interval

Conversion factor: To convert pounds to kilograms, multiply by 0.45

${ }^{*}$ Difference between incentive and control conditions significant at $P<.05$

lose $0,0.5$, or 1 pound/week for the remaining 8 weeks of the intervention. Since very few participants $(7 / 66)$ attained the initial goal, we were not able to examine with any statistical precision how participants did, given their secondary goals. For each of the 2 months in which participants could choose their own goals, $4 / 7$ chose 0 pounds per week.

Deposit Contract Contributions. The proportion of participants who contributed to deposit contracts did not differ between the incentive conditions; 95.5\% (42/44) of DC participants deposited money into deposit contracts initially. Although the proportion of participants contributing to deposit contracts decreased over time $(58.1 \%$ in month 8$)$, most participants made a deposit every month (mean number of months in which a deposit was made $=6.0, \mathrm{SD}=2.7$, median $=7.0$ ). Interestingly, from month 3 onward, although most DC participants did not attain their monthly weight loss goals, most continued to contribute to deposit contracts. For example, in month 3, only 34.9\% (15/43) of DC participants attained the goal, yet $69.8 \%(30 / 43)$ made a deposit for month 4. Although the likelihood of making a contribution in any given month was generally higher among those who had attained their goal in the preceding month, the likelihood of making a contribution was surprisingly high (>50\%) even among those who had not attained their goal on the preceding month (Fig. 3). Among participants not lost to follow-up, the average daily deposit contract contribution was $\$ 0.85$ (SD = 0.81); the median was $\$ 0.67(\mathrm{IQR}=0.83)$ and did not differ between incentive arms. When participants lost to follow-up are included, the average daily deposit contract contribution was $\$ 0.77(\mathrm{SD}=0.79)$; the median was $\$ 0.63$ $(\mathrm{IQR}=0.80)$.

Incentive Earnings. The average net incentive earnings was $\$ 88.18$ (SD = 117.64); the amount did not differ between DC groups. Of those who completed the study, the daily call-in rate was extremely high and the same between incentive conditions (99.9\%).

Long-Term Weight Loss Maintenance. Sixty-five percent of participants $[43 / 66$; Control $=14 / 22, \mathrm{DC}=29 / 44 ; \times 2(1)=$ 0.86, $P=0.86$ ] returned to the clinic for a follow-up weigh-in approximately 36 weeks after the last participant had completed the 32-week intervention (as with the primary endpoint, participants lost to follow-up were assumed to have reverted to baseline weight). There was substantial weight regain, particularly in the incentive conditions (mean $\mathrm{DC}=7.5$ pounds $95 \% \mathrm{CI}, 4.12$ to 10.95 ; mean $\mathrm{C}=0.90$ pounds, $95 \% \mathrm{CI}$, -4.86 to $6.67 ; t=2.14, P=0.04)$. Although the mean net weight loss between enrollment in the study and this point of longterm follow-up was larger in the incentive groups (1.2 pounds) than in the control group ( 0.3 pounds), this difference was not statistically significant $(t=0.31, P=0.76)$.

\section{DISCUSSION}

This is the first study to demonstrate that deposit contract incentives can successfully help keep weight off for 32 weeks, a result that appeared to be due to the duration of the intervention and not maintenance framing.

However, substantial weight was regained following cessation of the incentives and health and economic benefits require sustained weight loss. For this reason, devising techniques to promote weight loss maintenance following cessation of financial incentives is an important topic for future research. Success in improving health and economic outcomes through sustained weight loss may require augmenting this intervention with a more effective approach to habit formation.

This study contributes to evidence of the effectiveness of incentive systems based on behavioral economics in promoting weight loss. The intervention was designed to take advantage of several effects identified by behavioral economics, including over-

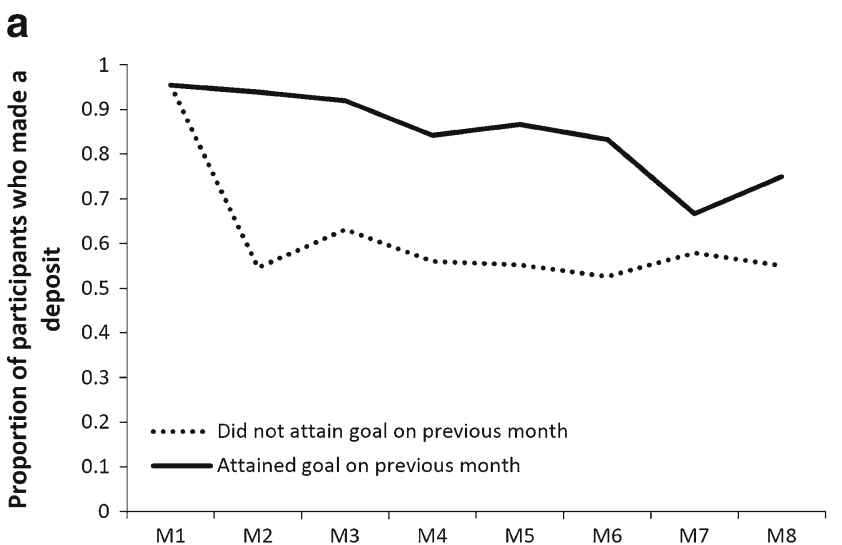

b

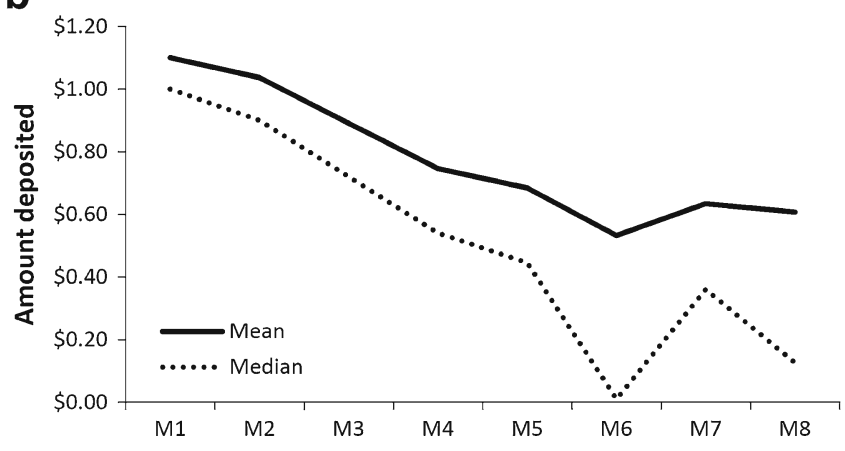

Figure 3. Deposit contracts: a) proportion of participants who made a contribution, by whether the weight loss goal had been attained in the month prior; b) Mean and median amounts deposited, by month. 
optimism ${ }^{12,13}$ and loss aversion. ${ }^{14}$ People tend to be over-optimistic in predicting their weight loss; therefore, when asked to put money down at the beginning of the month toward losing weight, most participants did so. Then, after having made a deposit, loss aversion was used to motivate weight loss, as participants did not want to lose the money they had deposited. Finally, consistent with research showing that even small rewards and punishments can have great incentive value if they occur immediately, ${ }^{15-18}$ participants received rapid feedback.

Interestingly, at 16 weeks our results were qualitatively similar to those of Volpp et al. ${ }^{7}$ Mean weight loss in the incentive conditions was 10.3 pounds (95\% CI, 7.1-13.5), compared to 13.1 (95\% CI, 2.0-16.4) and 14.0 (95\% CI, 3.7-16.4) pounds in the incentive arms in the study by Volpp et al. ${ }^{7}$ Similarly, in the present study, 34.1\% (95\% CI, 20.5\%-49.9\%) of incentive participants attained the 16-week weight loss goal; in Volpp et al.'s study, ${ }^{7}$ goal attainment rates in the incentive arms were $47.4 \%$ (95\% CI, 24.5\%-71.1\%) and 52.6\% (95\% CI, 28.9\%-75.6\%).

In this previous study, deposit contracts were supplemented with a \$3 direct payment per day, which was not included in the present study. ${ }^{7}$ Based on net incentive earnings and mean weight loss, the average cost per pound of weight loss was $\$ 10.14$ in the present study - much less than that of the deposit contract (\$27.04) and lottery incentive (\$20.82) arms of the Volpp et al.'s study. ${ }^{7}$

That most participants made a deposit each month, even though they usually did not attain their weight loss goal, is perhaps indicative of the pervasiveness of over-optimism. ${ }^{19}$ Failing to attain weight loss goals month after month did not deter people from making subsequent deposit contract contributions. This point attests to the utility in using decision errors to help people to attain their goals.

Although incentive participants lost more weight than controls, most did not attain their monthly weight loss goals. Not only were the goals ambitious, they became progressively more challenging because, as a proportion of total body mass, they increased over time, as participants lost weight. Future research could investigate the effectiveness of tapering goals off over time or of allowing participants to set their own goals.

That there was no effect of maintenance framing on weight loss could mean that framing does not matter, but it could also mean that the manipulation was too subtle. And, while maintenance framing may not affect weight loss, it may affect other important outcomes, such as attrition. For example, consistent with the goal-setting literature, breaking a weight loss program into different sub-components may make attaining overall weight loss goals seem less daunting, resulting in lower attrition rates. ${ }^{20}$ This conjecture is consistent with the current study: while four people withdrew from the condition in which the program was not broken into phases (DC2), only one person withdrew when such distinctions were made (DC1) $(P=0.035)$. Lost to follow-up rates were lower than is typical in weight loss studies, suggesting that this approach keeps participants engaged. The primary limitations of this study, discussed in that of Volpp et al., ${ }^{7}$ are: external validity (participants were predominantly male veterans motivated to lose weight); inability to determine the impact of feedback, independent from incentives, on weight loss; and the study staff could not be blinded due to the nature of the intervention. In summary, this article indicates that incentive approaches based on behavioral economics are effective in inducing weight loss over an 8-month interven- tion period. Future research is needed to devise techniques that promote sustained weight loss over longer periods of time.

Contributors: Daniel McDonald

Funders: USDA, Economic Research Service (grant no. 58-4000-70058) and the Hewlett Foundation.

Prior Presentations: Annual Meeting of the Society for General Internal Medicine, Minneapolis, May, 2010.

Conflict of Interest: None disclosed.

Corresponding Author: Leslie K. John, MS; Department of Social and Decision Sciences, Carnegie Mellon University, 208 Porter Hall, 5000 Forbes Avenue, Pittsburgh, PA 15213, USA (e-mail: lkjohn@andrew. cmu.edu).

\section{REFERENCES}

1. Ogden C, Carroll M, Curtin L, McDowell M, Tabak C, Flegal K. Prevalence of overweight and obesity in the United States. J Am Med Assoc. 2006;393(15):1549-55.

2. Jeffery RW, Thompson PD, Wing RR. Effects on weight reduction of strong monetary contracts for calorie restriction or weight loss. Behav Res Ther. 1978;16(5):363-9

3. Jeffery R, Drewnowski A, Epstein L. Long-term maintenance of weight loss. Health Psychol. 2000;19(1 Suppl):5-16.

4. NIH. (United States Department of Health and Human Services). NIH Guide: Findings of Scientific Misconduct. 2001 December 13, 2001.

5. Heshka S, Anderson J, Atkinson R, et al. Weight loss with self-help compared with a structured commercial program: a randomized trial. J Am Med Assoc. 2003;2003(289): 14.

6. Loewenstein G, Brennan T, Volpp KG. Asymmetric paternalism to improve health behaviors. J Am Med Assoc. 2007;298(20):2415-7.

7. Volpp K, John L, Troxel AB, Norton L, Fassbender J, Loewenstein G. Financial incentive-based approaches for weight loss: a randomized trial. J Am Med Assoc. 2008;300(22):2631-7.

8. Kahneman D, Tversky A. Prospect theory: an analysis of decision making under risk. Econometrica. 1979;47:263-91.

9. Ryan D, Espeland M, Foster G, et al. Look AHEAD (Action for Health in Diabetes): design and methods for a clinical trial of weight loss for the prevention of cardiovascular disease in type 2 diabetes. Control Clin Trials. 2003;24(5):610-28.

10. Ariely D, Wertenbroch K. Procrastination, deadlines, and performance: self-control by precommitment. Psychol Sci. 2002;13(3):219-24.

11. Knowler WC, Barrett-Connor E, Fowler SE, et al. Reduction in the incidence of type 2 diabetes with lifestyle intervention or metformin. N Engl J Med. 2002;346(6):393-403.

12. Svenson $\mathbf{O}$, Fischhoff B, MacGregor D. Perceived driving safety and seatbelt usage. Accident Analysis \& Prevention. 1985;17 (2):119-133.

13. Weinstein ND. Unrealistic optimism about susceptibility to health problems: Conclusions from a community-wide sample Journal of Behavioral Medicine. 1987;10(5):1573-3521.

14. Tversky A, Kahneman D. Loss aversion in riskless choice: a referencedependent model. Q J Econ. 1991;106(4):1039-61.

15. Ainslie G. Specious reward: a behavioral theory of impulsiveness and impulse control. Psychol Bull. 1975;82:463-96.

16. Thaler RH. Some empirical evidence on time inconsistency. Rev Econ Stud. 1981;23:165-80.

17. Loewenstein G, Prelec D. Anomalies in intertemporal choice: evidence and an interpretation. Q J Econ. 1992;107:573-97.

18. Kirby $\mathbf{K}$. Bidding on the future: evidence against normative discounting of delayed rewards. J Exp Psychol Gen. 1997;126:54-70.

19. Griffin D, Buehler R. Frequency, probability, and prediction: easy solutions to cognitive illusions? Cogn Psychol. 1999;38:48-78.

20. Locke EA, Latham GP. A theory of goal setting and task performance Englewood Cliffs. NJ: Prentice Hall; 1990. 